\title{
Penerapan Absensi QRCode Mahasiswa Bimbingan Belajar pada Website berbasis YII Framework
}

\section{Application Student Attendance QRCode in Guidance Learn to Website Based on Yii Framework}

\author{
Qurotul Aini $^{1}$, Yuliana Isma Graha ${ }^{2}$, Siti Ria Zuliana ${ }^{3}$ \\ ${ }^{1}$ Dosen STMIK Raharja Jurusan Sistem Informasi, ${ }^{2}$ Dosen STMIK Raharja Jurusan Sistem \\ Informasi, ${ }^{3}$ Mahasiswa STMIK Raharja Jurusan Sistem Informasi \\ $\underline{\text { aini@ } \text { raharja.info }}{ }^{1}, \underline{\text { iz@ raharja.info }}{ }^{2}, \underline{\text { siti.ria@ }{ }_{\text {raharja.info }}^{3}}$
}

\begin{abstract}
Abstrak
Dalam penyampaian informasi saat ini dibutuhkan sistem yang cepat dan mudah untuk diakses secara online anywhere and anytime yang diberikan harus selalu up to date. Perkembangan internet berkembang begitu pesat dan terus berinovasi dan menciptakan terobosan yang baru. Dalam meningkatkan kualitas sistem pembelajaran pada saat bimbingan belajar berlangsung yaitu sistem layanan absensi scanning qrcode untuk merekam kehadiran mahasiswa dengan baik. Dengan menggunakan sistem PenA (Penilaian Absensi) memberikan layanan dalam proses absensi scanning qrcode, menghindari terjadinya kecurangan yang dilakukan mahasiswa dimana mahasiswa dapat menitipkan absensi yang dilakukan oleh antar mahasiswa dalam bimbingan berlangsung. Dalam proses Absensi menggunakan PenA (Penilaian Absensi) akan merekam data Nim, Dosen Pembimbing, Ruangan Bimbingan, Waktu Kehadiran Bimbingan, Kode Unik Qrcode. Data masuk kehadiran mahasiswa dapat direkam dan berfungsi untuk menilai kedisiplinan serta kerajinan mahasiswa dalam melakukan bimbingan. Dalam perancangan sistem PenA (Penilaian Absensi) dengan mudah menggunakan website berbasis yii framework dan terdapat kelebihan seperti ukuran data yang dimiliki kecil, keamanan framework mengantisipasi perisai adanya berbagai permasalahan keamanan.
\end{abstract}

Kata kunci-Absensi Qrcode, Framework, Yii Framework

\begin{abstract}
In the current delivery of information required a fast and easy system to be accessed online anywhere and anytime given should always be up to date. The development of the internet developed so rapidly and continue to innovate and create new breakthroughs. In improving the quality of the learning system during the guidance of learning takes place the attendance service system scanning qrcode to record student attendance well. Using the PenA system (Attendance Assessment) provides services in the qrcode absence scanning process, avoiding the occurrence of fraud by students where students can entrust attendance by the students in guidance. In the Attendance process using PenA (Attendance Assessment) will record data Nim, Supervisor, Guidance Room, Time Attendance Guidance, Code Unique Qrcode. Data entry student attendance can be recorded and serves to assess the discipline and craft of students in conducting guidance. In the design of the PenA system (Attendance Assessment) easily using the yii framework based website and there are advantages such as small data size, security framework anticipates the shielding of various security issues.
\end{abstract}

Keywords - Absence Qrcode, Framework, Yii Framework 


\section{PENDAHULUAN}

Sistem tersebut pastinya akan membuat sebuah perubahan dari era yang manualisasi ke era yang pastinya lebih komputerisasi dalam berbagai bidang pendidikan, perkuliahan, dan lainlain. Era globalisasi yang membuat perkembangan teknologi sangat pesat memberikan pengaruh sangat besar bagi kehidupan manusia setiap bidang kehidupan. Dalam meningkatkan kualitas sistem pembelajaran pada bimbingan termasuk sistem layanan kehadiran mahasiswa. Kegiatan bimbingan belajar dapat berlangsung baik dan lancar dengan adanya mahasiswa yang sangat aktif untuk menghadiri setiap bimbingan belajar yang dijadwalkan.

Dalam memotivasi kegiatan belajar oleh mahasiswa harus memiliki penunjang semangat belajar nya dengan memberikan pelayanan Absensi mahasiswa dengan ada informasi hasil kehadiran mahasiswa dapat mengetahui kedisiplinan mahasiswa dan juga sebagai dosen pembimbing dapat memonitoring kehadiran mahasiswa dengan baik, mana yang tepat waktu ataupun terlambat.

Metode absensi dalam bimbingan juga sebelumnya mempunyai kelemahan dengan adanya kecurangan yang dilakukan mahasiswa dimana mahasiswa dapat menitipkan absensi yang dilakukan oleh antar mahasiswa dalam kelas. Kedisiplinan mahasiswa tidak terpantau dengan baik saat melakukan bimbingan belajar yang dijadwalkan.

Adapun Penelitian yang sudah dilakukan banyak sekali mengenai sistem absensi. Pengembangan sistem absensi ini melakukan lima tinjauan pustaka terhadap penelitian terdahulu untuk menjadi pedoman di dalam pengembangan ini, yaitu: Penelitian mengenai aplikasi Absensi Pegawai Kecamatan Batuceper Tangerang Dalam Meningkatkan Akurasi Informasi[5]. Penelitian ini menjelaskan perihal Kecamatan Batuceper yang merupakan instansi pemerintahan yang sistem absensi pegawainya masih berjalan secara manual. Dimana dalam penerapan sistem absensi ini terdapat beberapa hal yang menjadi kendala. Adapun kendala yang terjadi yaitu dalam hal keefektifan, efisiensi waktu dan proses Absensi.

Penelitian selanjutnya mengenai aplikasi Absensi Siswa Menggunakan Sidik Jari di Sekolah Menengah Atas Negeri 9 Manado[1]. Penelitian ini menjelaskan perihal perkembangan ilmu pengetahuan di segala bidang dalam era globalisasi saat ini begitu pesat terutama dalam bidang IT yang semakin maju seiring dengan kebutuhan pemakai (user). Absensi merupakan salah satu penunjang yang dapat mendukung atau memotivasi setiap kegiatan yang dilakukan di dalam dunia pendidikan di Indonesia. Selanjutnya penelitian tentang rancang Bangun Sistem Absensi Karyawan Online Berbasis Web Menggunakan Framework PHP Codeigniter \& Mysq1 (Studi Kasus: PT. Starone Mitra Telekomunikasi)[2]. Penelitian ini membahas tentang PT Star One Mitra Telekomunikasi masih menerapkan sistem absen petunjuk sebagai sistem karyawan kehadiran pada hari ini, dilaksanakan untuk setiap karyawan dalam lembar bentuk kehadiran disediakan sehari-hari. Seiring dengan berjalannya waktu dengan, sistem ini terbukti persyaratan kurang efisiensi dan akurasi data. Penelitian lainnya tentang pembuatan Aplikasi Presensi Perkuliahan Berbasis Fingerprint (Studi Kasus : Jurusan Sistem Informasi Institut Teknologi Sepuluh Nopember Surabaya) [6]. Penelitian ini membahas tentang Jurusan Sistem Informasi Institut Teknologi Sepuluh November Surabaya (JSI ITS) dewasa ini telah menerapkan sistem absensi berbasis fingerprint. Selanjutnya dilakukan Penelitian mengenai Sistem Informasi Manajemen Kepegawaian Berbasis Web pada PT Bintang Baru Sejati Palembang[4]. Penelitian ini menjelaskan Sistem Informasi Manajemen merupakan penerapan sistem informasi di dalam organisasi untuk mendukung informasi-informasi yang dibutuhkan oleh semua tingkatan manajemen.

Berdasarkan penelitian sebelumnya bahwa penelitian mengenai sistem absensi dalam membuat laporan rekapan kehadiran, tetapi belum ada penelitian yang secara khusus membahas mengenai Perancangan Absensi Menggunakan Scanning Qrcode untuk Mahasiswa saat melakukan Bimbingan Belajar Berbasis Web dengan Menggunakan Yii Framework. 


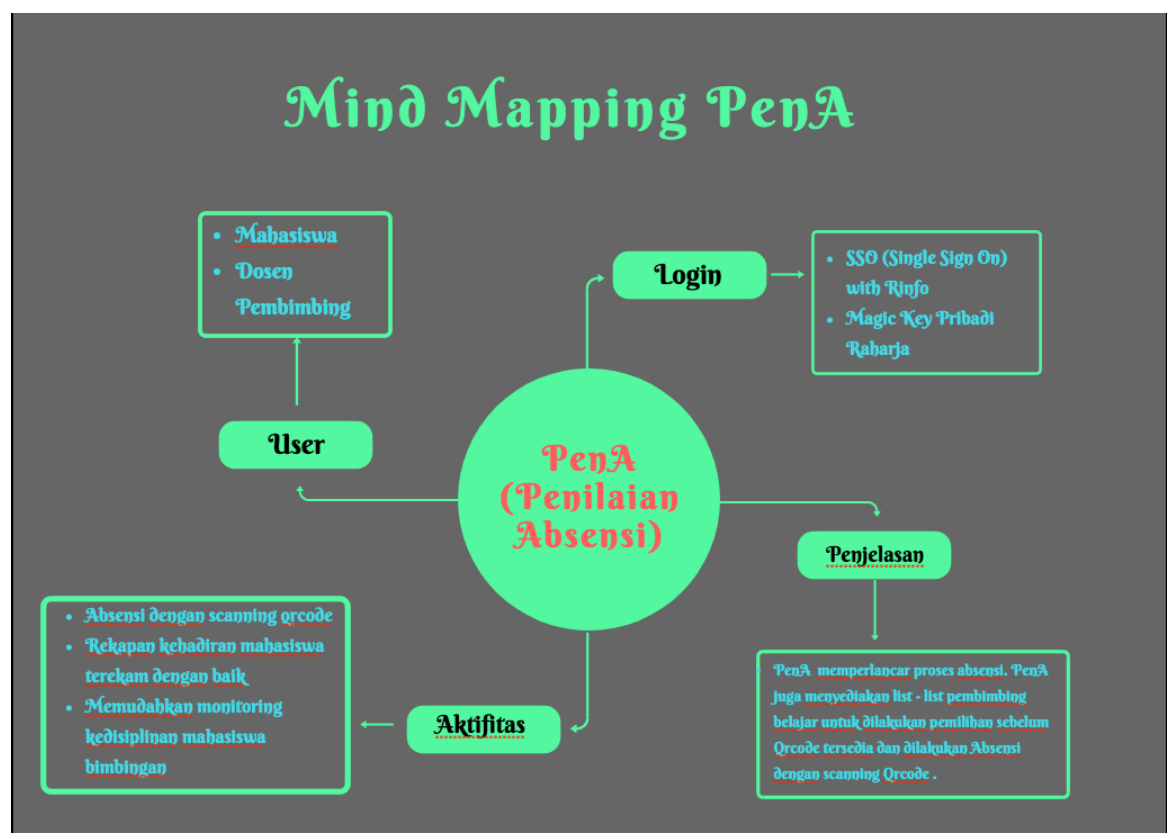

Gambar 1. Mind Mapping PenA.

Gambar di atas merupakan tampilan Mind Mapping atau gambar pemetaan pikiran yang menjelaskan deskripsi tentang PenA (Penilaian Absensi) yaitu (1) Penjelasan ini menjelaskan tentang fungsi utama dari sistem PenA adalah Memperlancar proses absensi. PenA juga menyediakan list - list pembimbing belajar untuk dilakukan pemilihan sebelum Qrcode tersedia dan dilakukan Absensi dengan scanning Qrcode . (2) Sistem PenA dapat Login dengan SSO (Single Sign On/Out) with Rinfo artinya hanya menggunakan satu kunci yaitu akun Rinfo yang dimiliki Pribadi Raharja sebagai Magic Key. (3) User yang terdapat dalam sistem PenA memiliki 2 user diantaranya Mahasiswa dan Dosen Pembimbing (4) Aktivitas yang dilakukan oleh user dalam menggunakan PenA yaitu Absensi dengan scanning qrcode kemudian mendapatkan rekapan kehadiran mahasiswa terekam dengan baik serta memudahkan dosen pembimbing monitoring kedisiplinan mahasiswa bimbingan.

Untuk merancang Sistem PenA ( Penilaian Absensi ) berbasis website menggunakan Yii framework. Yii mengimplementasikan pola desain model view controller (MVC) yang diadopsi secara luas dalam pemrograman web. MVC bertujuan untuk memisahkan logika bisnis dari pertimbangan antarmuka pengguna agar para pengembang bisa lebih mudah mengubah setiap bagian tanpa mempengaruhi yang lain. Dalam MVC, model menggambarkan informasi (data) dan aturan bisnis: view (tampilan) berisi elemen antar muka pengguna seperti teks, input form. Sementara controller mengatur komunikasi antar model dan view.

Selain implementasi MVC, Yii juga memperkenalkan front controller controller depan), yang disebut Application, yang mengenkapsulasi konteks eksekusi untuk memproses sebuah request. Application mengumpulkan beberapa informasi mengenai request pengguna dan kemudian mengirimnya ke controller yang sesuai untuk PENA (Penilaian Absensi) penanganan selanjutnya. 


\section{METODE PENELITIAN}

Dalam merancang sebuah sistem hal penting yang diperlukan yaitu memperhatikan 7 hal untuk mengatasi berbagai masalah yang ada di atas maka didalam tahapan - tahapan penelitian diterapkan beberapa metode. Dalam penelitian ini metode penelitian yang diterapkan adalah Perumusan masalah, Perancangan Penelitian, Pengumpulan Data, Pengolahan Data, Penyajian Data, Analisis Data, Laporan Penelitian.

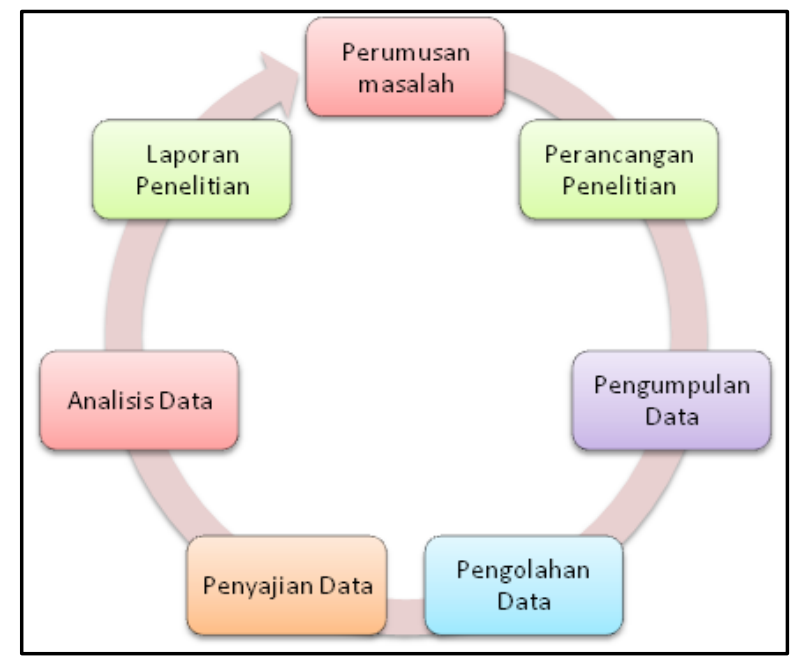

Gambar 2. Metode Penelitian

\section{Keterangan :}

a. Perumusan masalah

Observasi agar mengetahui permasalahan yang terjadi pada sistem yang sebelumnya berjalan.

b. Perancangan Penelitian

Merancang konsep sistem PenA dalam bentuk prototype agar mudah dalam pemahaman saat diterapkan dalam website berbasis yii framework

c. Pengumpulan Data

Menyiapkan Data yang diperlukan dalam perancangan PenA misalkan Data Mahasiswa, Data Pembimbing, dan juga Data Ruangan yang dilakukan penyimpanan dalam sebuah database.

d. Pengolahan Data

Melakukan integrasi dari berbagai data data yang tersimpan dalam database untuk mendukung website pena yang dirancang.

e. Penyajian Data

Data yang sudah diolah akan ditampilkan sebagai informasi yang berguna bagi Mahasiswa dan pastinya bagi Pembimbing belajar. Data yang disajikan pastinya harus jelas dan mudah dipahami contohnya dalam bentuk diagram, grafik, tabel.

f. Analisis Data

Menganalisa hasil dari proses awal perumusan masalah, mengetahui penyebab dari masalah yang timbul

g. Laporan Penelitian

Melaporkan seluruh hasil penelitian secara mendetail yang akhirnya terselesaikan permasalahan yang ada dengan baik. 


\section{HASIL DAN PEMBAHASAN}

Pada bagian ini dibahas mengenai analisa kebutuhan dari sistem yang dirancang. Berdasarkan analisa yang dihasilkan, dilanjutkan dengan melakukan perancangan yang terdiri atas perancangan sistem, perancangan basis data serta perancangan antarmuka sistem. Terakhir implementasi sistem dan menyajikan screenshoot sistem absensi kehadiran mahasiswa dalam bimbingan belajar.

\subsection{Analisa Permasalahan}

Absensi yang berjalan pada Perguruan Tinggi Raharja sudah cukup baik namun dengan absen klik di panel kehadiran (Local Host) pada dekstop kurang efisien karena banyaknya waktu yang terbuang untuk absensi saja. Kegiatan belajar mengajar pun kurang efektif karena pemberian materi sering terpotong oleh absensi mahasiswa yang telat masuk perkuliahan. Selain itu data yang dihasilkan masih belum akurat karena mahasiswa bisa menitipkan absen kehad

iran.

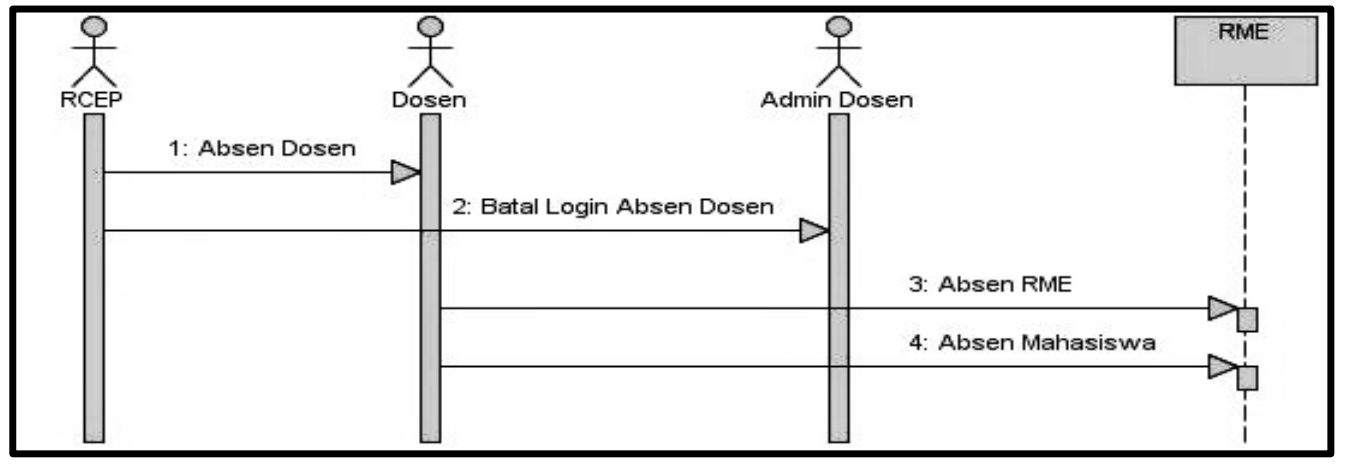

Gambar 3. Sequence Diagram Sistem yang Berjalan

Penjelasan mengenai Gambar di atas merupakan tampilan alur absensi kehadiran yang berjalan dari Dosen melakukan Absensi hingga dilanjutkan oleh mahasiswa yang melakukan Absensi. Adapun dari gambar alur di atas terdapat 3 aktor dan memiliki tugas yang berbeda diantaranya yaitu RCEP, dosen, dan Admin Dosen. Tugas yang dimiliki setiap aktor berbeda beda yaitu Dosen mendatangi bagian buka absensi yang disebut dengan RCEP, kemudian setelah Dosen buka kelas, dosen segera mengakses halaman absensi dan selanjutnya mahasiswa akan di absensi oleh dosen satu per satu yang akan menggunakan waktu yang banyak serta akan mengganggu waktu belajar. Admin Dosen bertugas memonitoring kehadiran dosen dan mahasiswa namun proses bertugas memonitoring serta merekap masih manual dan harus menggunakan ketelitian yang sangat tinggi.

\subsection{Pemecahan Permasalahan}

Penjelasan masalah yang terjadi pada alur absensi yang berjalan sangat terinci maka dari itu terdapatlah sistem yang akan meminimalisir permasalahan tersebut yaitu PenA (Penilaian Absensi) guna memperlancar proses absensi. PenA (Penilaian Absensi) juga menyediakan list - list pembimbing belajar untuk dilakukan pemilihan sebelum Qrcode tersedia. 


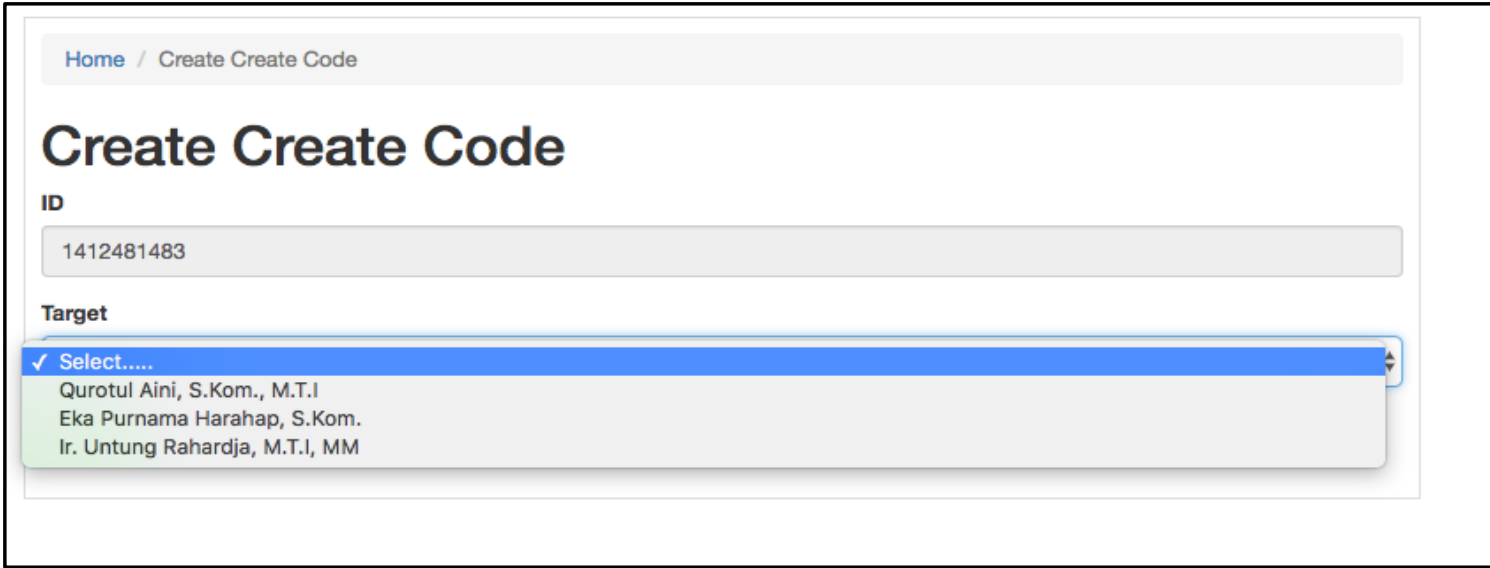

Gambar 4. Pemilihan Nama Dosen Pembimbing

Dengan konsep Absensi PenA (Penilaian Absensi) menggunakan Scanning Qrcode akan meminimalisir permasalahan yang ada, menghindari penitipan absensi antar teman terjadi dikarenakan Qrcode yang disediakan memiliki Unique ID maka setiap mahasiswa ingin melakukan absensi akan memiliki Qrcode dengan Unique ID yang berbeda - beda dan Qrcode tersebut hanya bisa digunakan $1 \mathrm{x}$ dalam waktu 10 menit yang sudah ditentukan.

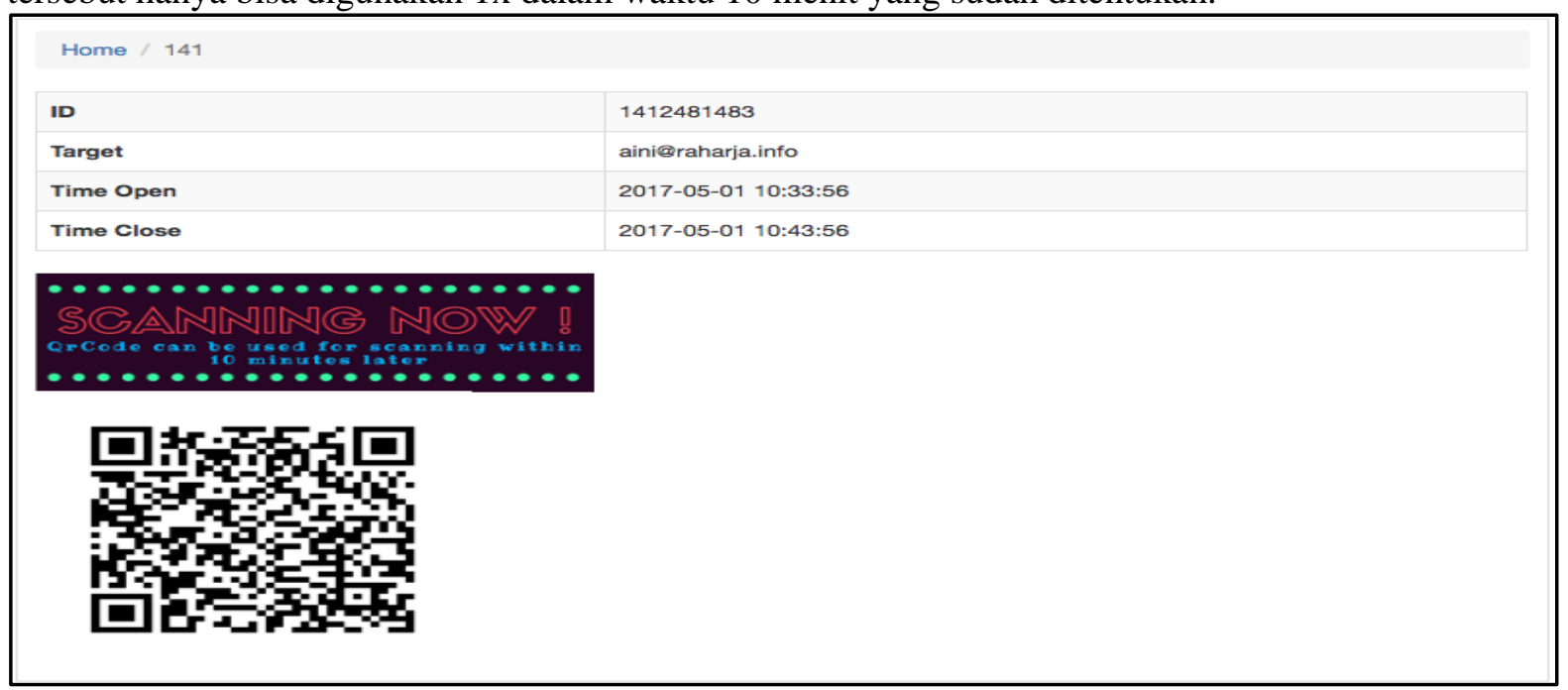

Gambar 5. QRCode yang Tersedia untuk dilakukan Scanning

Terdapat informasi jelas mengenai nim mahasiswa yang melakukan Generate Qrcode juga terdapat Nama Dosen Pembimbing yang ingin dilakukan bimbingan serta waktu berlaku dan berakhirnya Qrcode. Qrcode yang sudah tersedia siap untuk dilakukan scanning untuk melakukan Absensi kehadiran.

\subsection{Cara membuat Qr code berdasarkan NIM}

QRcode merupakan singkatan dari Quick Respone code. Penggunaan barcode dua dimensi sudah sangat luas, namun umumnya di pakai untuk mengkodekan alamat website, nomor contact, alamat email, nomor telepon atau sekedar teks biasa.

Alat yang digunakan untuk membaca QRCode disebut QRCode Scanner yang tersedia dalam bentuk aplikasi di smartphone seperti Android atau iPhone. Tujuan utama QRCode saat 
ini digunakan untuk memudahkan pengguna Smartphone mengakses informasi dengan dua langkah mudah, 1. scanning QRcode, 2 lakukan absensi kehadiran

Untuk membaca pesan yang tersembunyi di QRCode anda bisa memanfaatkan aplikasi bernama QRCode scanner yang bertebaran di Android Market atau Appstore. Android sendiri mempunyai banyak sekali tool QRcode scanner. Namun dari semua Aplikasi yang tersedia di Android Market.

Alat pembaca QRcode seperti Scanner buatan ZXing sudah menyediakan QRCode generator untuk membuat QRcode dari contact, Bookmark (URL), Aplikasi atau teks yang anda ketik sendiri.

Tahapan awal untuk melakukan pembuatan QRCode yaitu dengan membuka file FTP (File Transfer Protocol), penulis menggunakan fasilitas dari code any where untuk melakukan editing coding, lalu membuat model sesuai tabel field yang diperlukan.

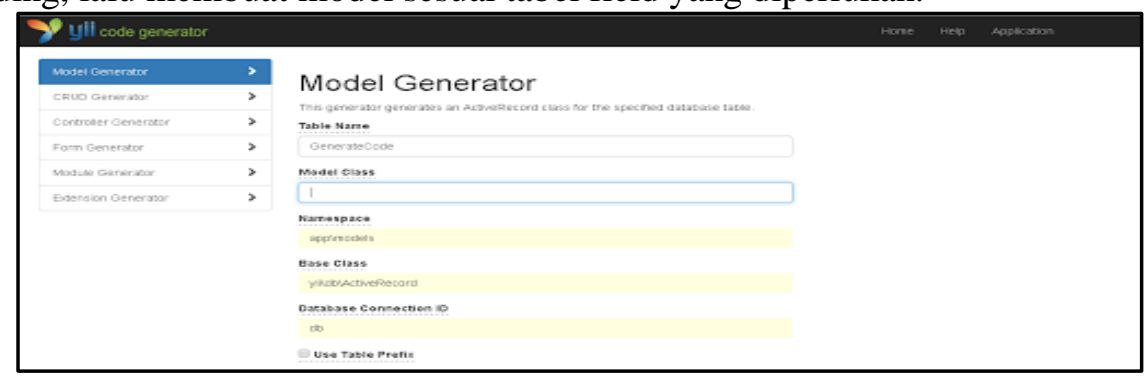

Gambar 6. Membuat Model sesuai Tabel Field yang diperlukan

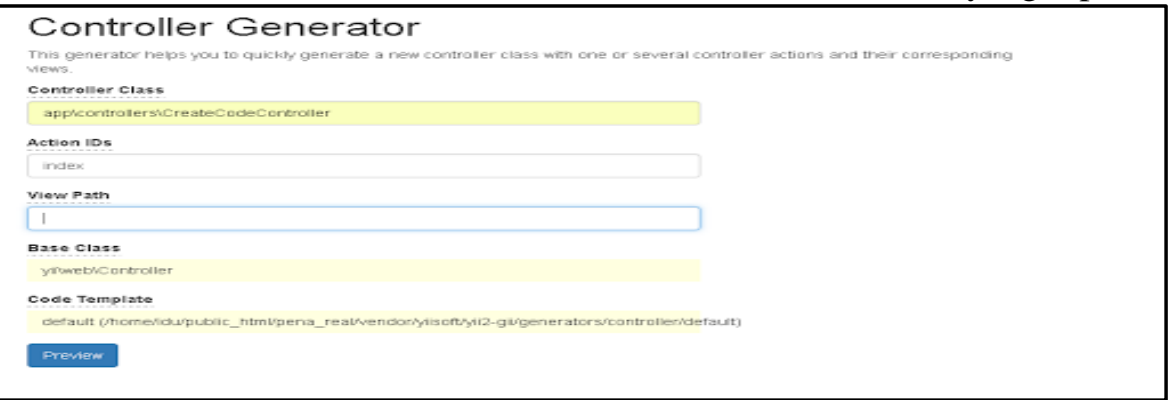

Gambar 7. Membuat Controller sesuai yang diperlukan

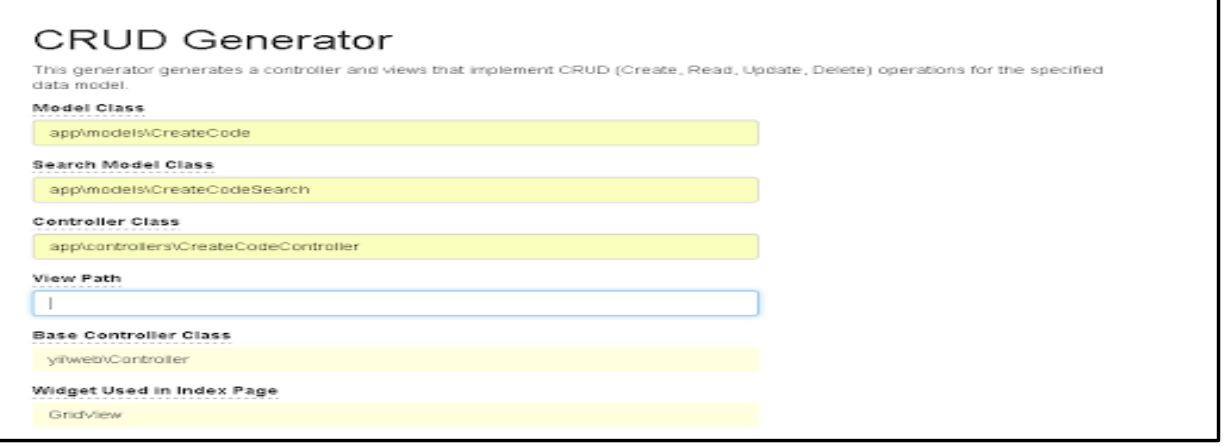

Gambar 8. Proses pembuatan CRUD 
Penerapan Absensi QRCode Mahasiswa Bimbingan Belajar...

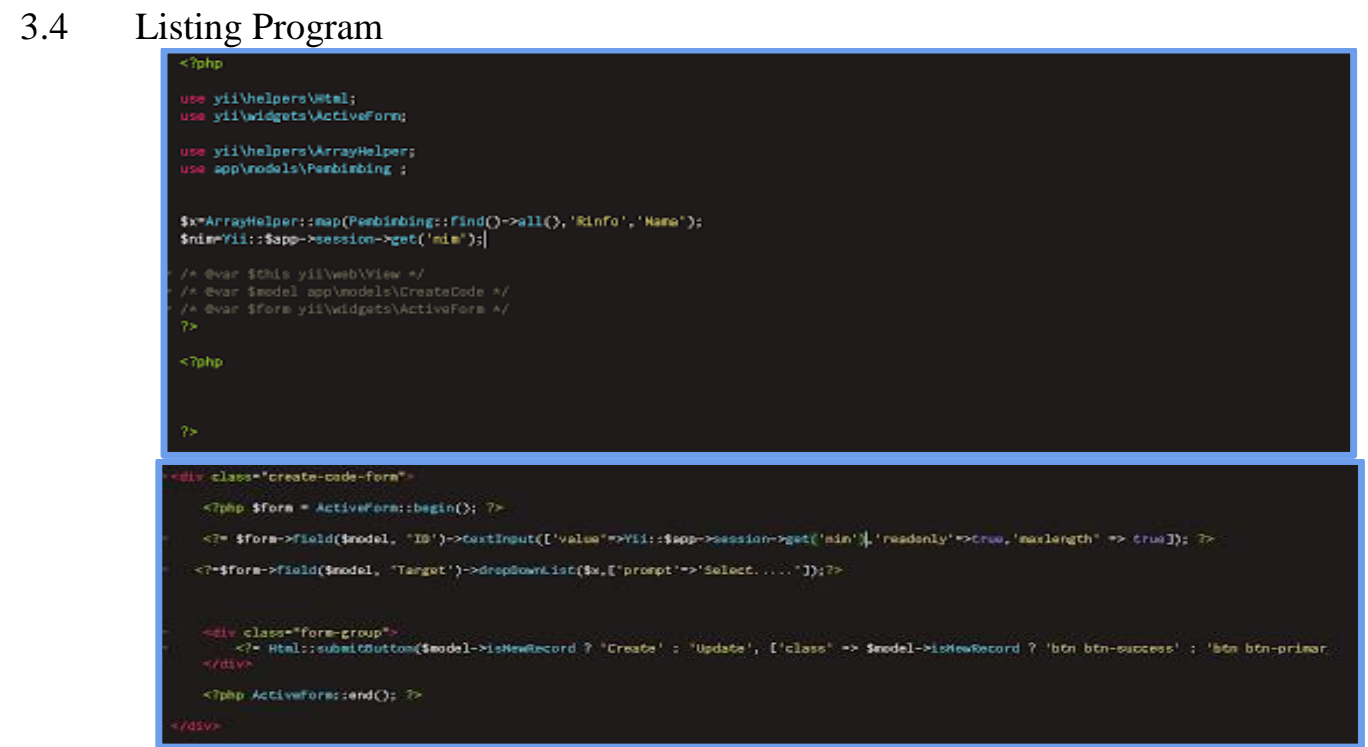

Gambar 9. Proses Konfigurasi From CRUD

Pada Script Php Query kan tabel pembimbing sertakan attribute rinfo dan nama dan ambil NIM dari session. Pada Script Html masukan value nya pada class Form.

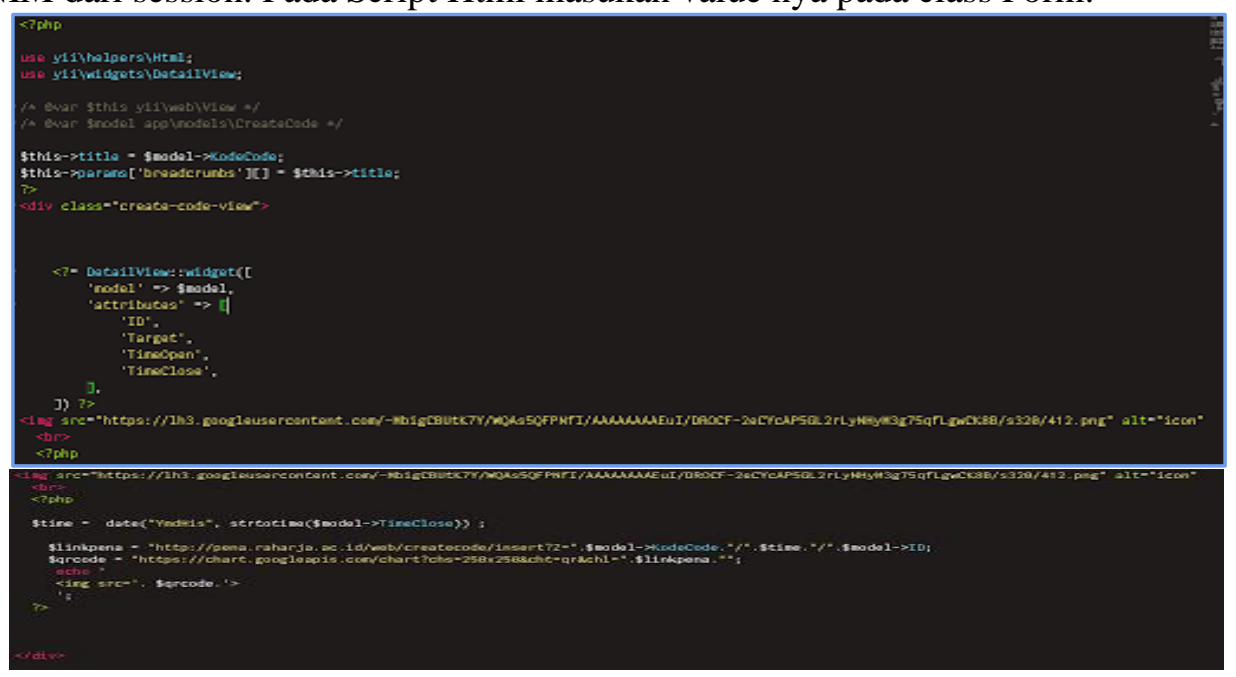

Gambar 10. Proses Konfigurasi View pada CRUD

Pada Script Php dibuat kan link dimana sudah ada attribute nama pembimbing serta NIM yang akan direct ketika Qrcode di scanning, lalu visualisasikan menggunakan chart google, masih dalam Script Php, sertakan waktu saat user buat Qrcode nya. 


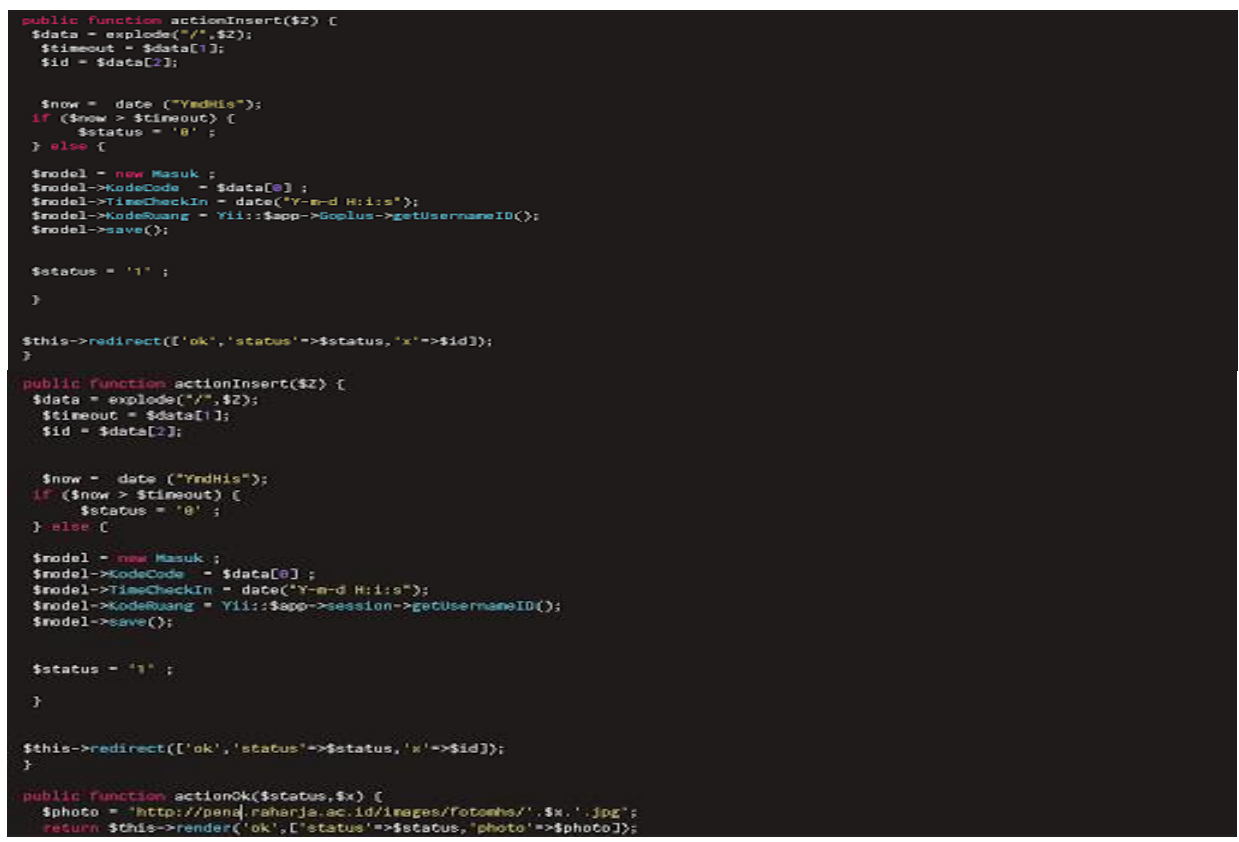

Gambar 11. Createcodecontroller pada folder Controller

Pada function create ambil parameter apa saja yang ingin di save pada database, lalu tambahkan variable waktu yang ditentukan qrcode itu bisa di scanning atau tidak, lalu pecahkan dengan script explode pada function insert, tambahkan script IF untuk mengecek sesuai tidak dengan variable waktu yang ditentukan, apabila jawaban dari pengecekan if, adalah iya, data akan disimpan pada database, jawaban dari if akan di visualisasikan ke OK.php

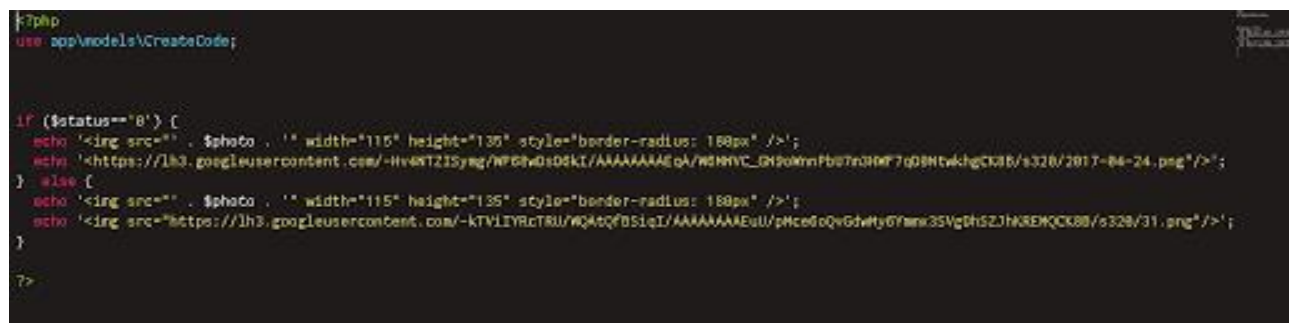

Gambar 12. Konfigurasi Ok pada folder (Nama CRUD)

Apabila jawaban if dari createcodecontroller iya atau tidak maka akan dinyatakan pada Ok.php ini, file ini seperti status atau keterangan.

\subsection{Implementasi}

Perancangan sistem berupaya menganalisa input data atau aliran data secara sistematis, memproses atau mengirimkan data, menyimpan data, dan menghasilkan informasi. Perancangan sistem digunakan untuk menganalisa, merancang, dan mengimplementasikan peningkatan peningkatan fungsi yang bisa dicapai melalui penggunaan sistem informasi terkomputerisasi. 
Penerapan Absensi QRCode Mahasiswa Bimbingan Belajar...

a. Halaman Utama

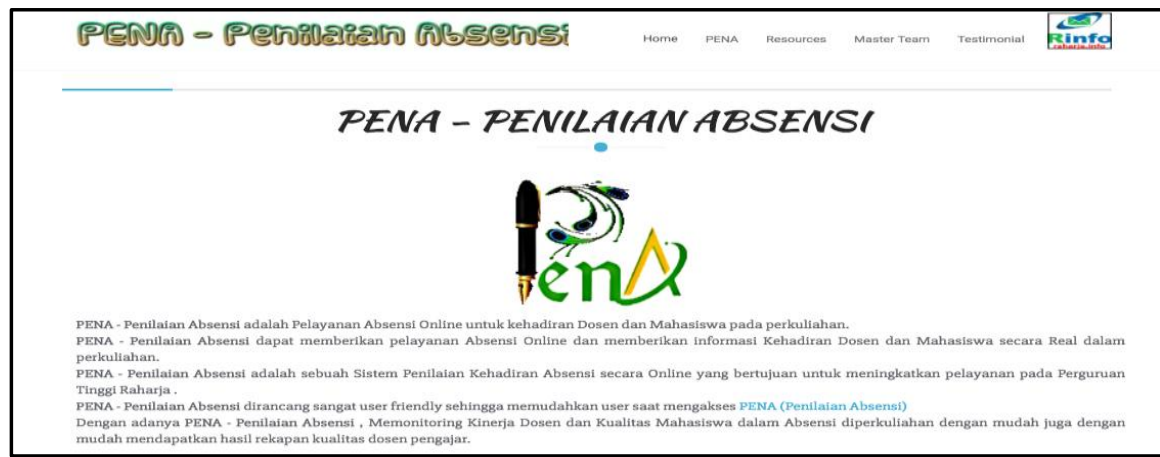

Gambar 13 . Halaman Homepage Website PenA

Menu Utama menjelaskan halaman utama dari website PenA yaitu http://pena.raharja.ac.id/

b. Tampilan untuk membuat Qrcode

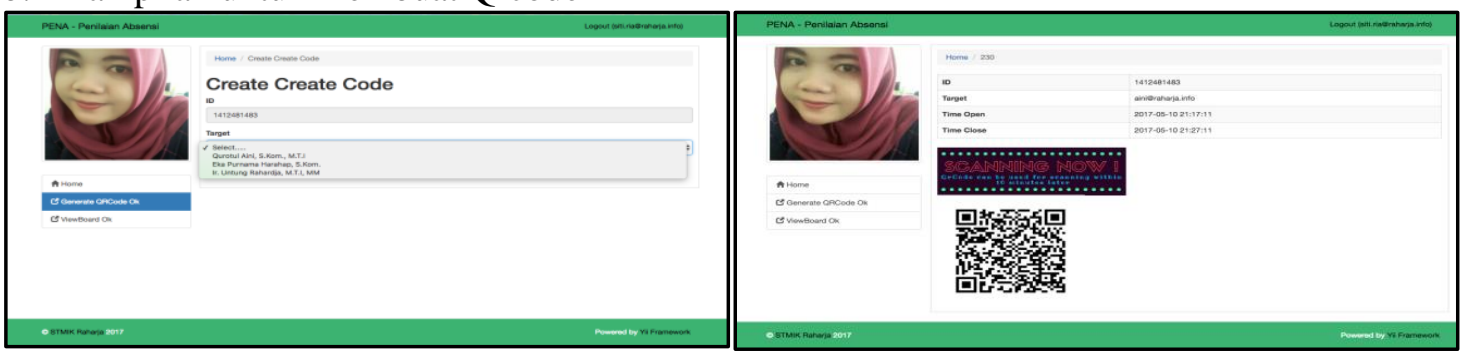

Gambar 14 . Halaman untuk membuat Qrcode

Halaman untuk membuat Qrcode menjelaskan halaman untuk mahasiswa memilih dosen pembimbing dari website PenA kemudian terdapat QRCode yang siap untuk dilakukan scanning absensi.

c. Tampilan Rekapan Absensi

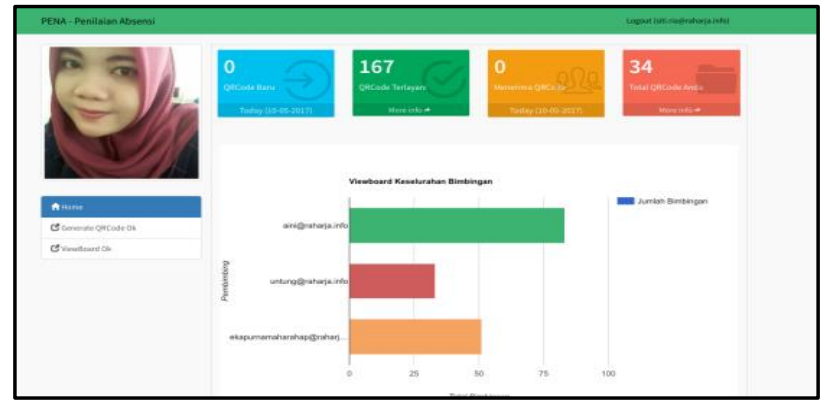

Gambar 15 . Grafik hasil Rekapan Absensi 


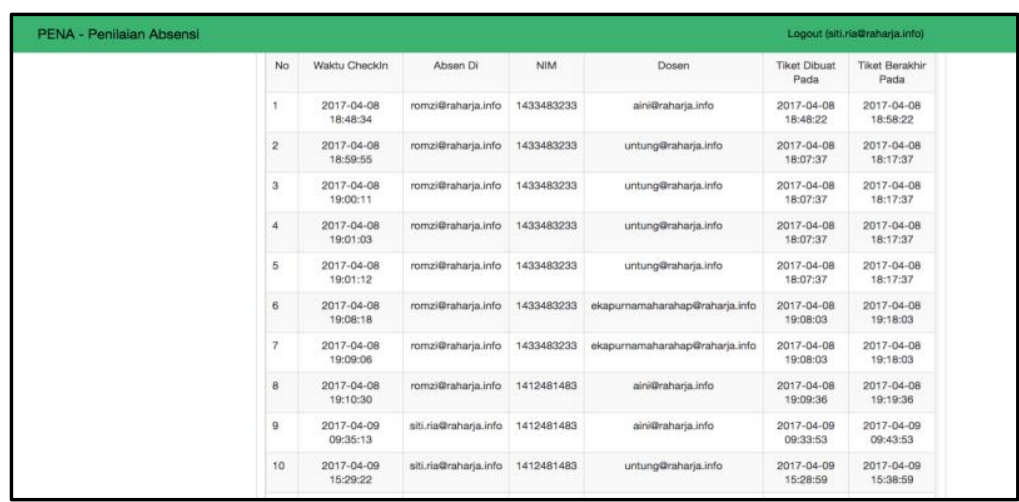

Gambar 16 . Tabel hasil Rekapan Absensi

Pada gambar diatas menjelaskan halaman rekapan absensi, saat dilakukan scanning absen berhasil kemudian data masuk ke dalam database dan tampil pada website PenA dengan laporan berbentuk Grafik dan Tabel.

\section{KESIMPULAN}

Dalam penerapan absensi qrcode mahasiswa bimbingan belajar pada website berbasis yii framework ini mendapatkan 3 kesimpulan yaitu:

a. Aplikasi Absensi dengan Scanning QRCode Mahasiswa lembaga pendidikan berbasis Web ini adalah media yang dapat digunakan untuk menyampaikan informasi khususnya pada pimpinan dan pembimbing serta mahasiswa.

b. Aplikasi absensi peserta ini dirancang penulis dengan menggunakan Website berbasis Framework Yii, xampp sebagai web server nya, PHP bahasa scripting-nya dan MySQL sebagai database manajemen sistem (DBMS).

c. Rekapan Absensi, memudahkan Pimpinan dan Pembimbing mahasiswa mendapatkan rekapitulasi absensi secara online, dan data absensi lebih terstruktur dan tidak akan mudah tercecer lagi, karena sudah tersimpan secara terintegrasi melalui pengolahan database yang baik.

\section{SARAN}

Berdasarkan dari penjelasan yang telah penulis uraikan sebelumnya, maka penulis dapat menyimpulkan saran dari penjelasan tersebut, antara lain:

a. Pengembangan selanjutnya akan terdapat fitur fitur yang lebih lengkap dan memudahkan user dalam menggunakan website ini

b. Pengembangan selanjutnya juga dalam bentuk Mobile sehingga memudahkan akses melalui gadget handphone dan pastinya dibuatkan mobile yang user friendly.

\section{UCAPAN TERIMA KASIH}

Penulis mengucapkan terima kasih kepada Perguruan Tinggi Raharja yang telah memberi dukungan finansial terhadap penelitian ini. 


\section{DAFTAR PUSTAKA}

[1] S. Rintjap, Sherwin R.U.A, Sompie, and O. Lantang, "Aplikasi Absensi Siswa Menggunakan Sidik Jari di Sekolah Menengah Atas Negeri 9 Manado". Manado: Jurnal Teknik Elektro Dan Komputer UNSRAT Universitas Sam Batulangi Manado, 2014.

[2] A. T. Satria, "Rancang Bangun Sistem Absensi Karyawan Online Berbasis Web Menggunakan Framework PHP Codeigniter \& Mysql (Studi Kasus: PT. Starone Mitra Telekomunikasi)". Semarang: Jurnal TransIT Universitas Semarang Vol. 1 No. 1 pp. 5365, Januari 2013.

[3] B. Permana, "Cepat Mahir Bahasa Pemrograman PHP". Diambil dari: http://ilmukomputer.org/wpcontent/uploads/2013/01/BudiCepat-Mahir-BahasaPemrogramanPHP.pdf, Diakses 9 Februari 2015.

[4] L. Anjaya, R. Lukito, and E. S. Djatikusuma, "Sistem Informasi Manajemen Kepegawaian Berbasis Web pada PT Bintang Baru Sejati Palembang". Palembang: STMIK GI MDP, 2010.

[5] M. Rachman and C. A. W. Dini, "Aplikasi Absensi Pegawai Kecamatan Batuceper Tangerang Dalam Meningkatkan Akurasi Informasi”. Tangerang: CCIT ISSN : 1978 8282 Vol.9 No.1 - September 201559 Journal Perguruan Tinggi Raharja Vol. 7 No. 2, Januari 2014.

[6] N. A. Muhammad, F. Samopa, and R. P. Wibowo, "Pembuatan Aplikasi Presensi Perkuliahan Berbasis Fingerprint (Studi Kasus : Jurusan Sistem Informasi Institut Teknologi Sepuluh Nopember Surabaya)". Surabaya: Jurnal Teknik POMITS Institut Teknologi Sepuluh November Vol. 2 No.3, 2013.

[7] R. Budi, "Belajar Otodidak Membuat Database Menggunakan MySQL." Bandung : Informatika, 2011.

[8] Yulianto, "Pengembangan SIS+ Pada Perguruan Tinggi Raharja Studi Kasus: Daftar Nilai dan Biodata Menggunakan Yii Framework". Tangerang: Laporan Skripsi, 2013.

[9] Mulyandi Rachman, Cynthia Ayu Wulan Dini. Januari 2014. "Aplikasi Absensi Pegawai Kecamatan Batuceper Tangerang Dalam Meningkatkan Akurasi Informasi". Tangerang. Jurnal CCIT. Vol 7 No 2.

[10] S. Rintjap, Sherwin R.U.A, Sompie, and O. Lantang, "Aplikasi Absensi Siswa Menggunakan Sidik Jari di Sekolah Menengah Atas Negeri 9 Manado". Manado: Jurnal Teknik Elektro Dan Komputer UNSRAT Universitas Sam Batulangi Manado, 2014.

[11] A. T. Satria, "Rancang Bangun Sistem Absensi Karyawan Online Berbasis Web Menggunakan Framework PHP Codeigniter \& Mysql (Studi Kasus: PT. Starone Mitra Telekomunikasi)". Semarang: Jurnal TransIT Universitas Semarang Vol. 1 No. 1 pp. 53 - 65, Januari 2013.

[12] N. A. Muhammad, F. Samopa, and R. P. Wibowo, "Pembuatan Aplikasi Presensi Perkuliahan Berbasis Fingerprint (Studi Kasus : Jurusan Sistem Informasi Institut Teknologi Sepuluh Nopember Surabaya)". Surabaya: Jurnal Teknik POMITS Institut Teknologi Sepuluh November Vol. 2 No.3, 2013.

[13] L. Anjaya, R. Lukito, and E. S. Djatikusuma., "Sistem Informasi Manajemen Kepegawaian Berbasis Web pada PT Bintang Baru Sejati Palembang”. Palembang: STMIK GI MDP, 2010. 